\title{
Severe Varicella Pneumonia in Adults: Seven Years' Single-center Experience from India
}

\author{
Akashdeep Singh, Siddharth Parkash', Sunil K Gupta², R. K. Soni ${ }^{3}$ \\ Departments of Pulmonary Medicine, ${ }^{1}$ Radiology, ${ }^{2}$ Dermatology and ${ }^{3}$ Community Medicine, Dayanand Medical College and Hospital, Ludhiana, Punjab, India
}

\section{Abstract}

Context: Varicella pneumonia is a rare but a serious complication of chickenpox in adults. There is paucity of data on varicella pneumonia from India. Aims: The aim of this study is to describe the clinical manifestations, hospital course, treatment, and outcome of adult patients with severe varicella pneumonia. Settings and Design: This was a retrospective, observational study of patients with severe varicella pneumonia attending a tertiary care teaching hospital. Subjects and Methods: The cases of varicella were identified by a computerized search of the medical record for the period between January 2010 and December 2016. During this period, 137 patients got admitted with varicella of which 22 had severe varicella pneumonia. Statistical Analysis: Mean and standard deviation were computed. Fisher's Z-test of proportions and analysis of variance were applied. Results: There were 17 (77.3\%) men and 5 (22.7\%) women. The mean age of the patients was $33.4 \pm 10.8$ years. History of contact with an infected person followed by high-grade fever and typical rash was present in all patients. Forty-five percent (10/22) of patients were immunosuppressed. All the patients received intravenous acyclovir. Forty-five percent (10/22) of patients received invasive mechanical ventilation. The various factors associated with the need for mechanical ventilation were partial pressure of oxygen:fraction of inspired oxygen ratio $<150$, quick sequential (sepsis-related) organ failure assessment (qSOFA) $>2$, and early bacterial coinfection. The mean Intensive Care Unit and hospital stay were 7 days (range; 1-16) and 9 days (range; 4-21), respectively. The overall mortality was $22.7 \%$ and reached $50 \%$ in those requiring invasive ventilation. The mortality was higher among patients with qSOFA $>3$, mean arterial blood pressure $<60 \mathrm{mmHg}$, and severe acute respiratory distress syndrome at presentation. Conclusions: Patients with severe varicella pneumonia are at an increased risk of respiratory failure and death.

Keywords: Mechanical ventilation, respiratory failure, varicella pneumonia

\section{INTRODUCTION}

Varicella (chickenpox) is an exanthematous, highly communicable airborne viral disease of childhood which usually has a benign course. However, severe infection, serious complication, and mortality can develop, especially in newborn babies, adolescents, adults, pregnant women, and immunosuppressed individuals of any age. ${ }^{[1]}$

The mortality for varicella ranges $0.29-0.46$ per 1 million. Following the introduction of the varicella vaccine in 1995, there has been a significant decline in the incidence, hospitalizations, and deaths, especially in the developed countries. ${ }^{[2,3]}$

Pneumonia, though rare, is the most serious complication of chickenpox infection in healthy adults. ${ }^{[3]}$ The respiratory complications of varicella are almost 25 -fold more common

\begin{tabular}{|l|l|}
\hline \multicolumn{3}{c|}{ Access this article online } \\
\hline Quick Response Code: & Website: \\
& www.ijccm.org \\
& \\
&
\end{tabular}

in adults than in children. Varicella pneumonia is estimated to occur in 1 in 400 cases of infection. ${ }^{[4,5]}$ According to another analysis, the incidence of pneumonia in varicella is $<1.5 / 100,000$ per year. ${ }^{[6]}$

Various established risk factors for developing varicella pneumonia include history of contact with a patient having chickenpox, previous or current smokers, chronic lung diseases, impaired immune status, severity of the skin rash, and third trimester of pregnancy. ${ }^{[3,5]}$ The estimated mortality for varicella pneumonia varies between $10 \%$ and $33 \% .{ }^{[7]}$ The

Address for correspondence: Dr. Akashdeep Singh, Department of Pulmonary Medicine, Dayanand Medical College and Hospital, Ludhiana - 141 001, Punjab, India. E-mail: drsinghakashdeep@gmail.com

This is an open access journal, and articles are distributed under the terms of the Creative Commons Attribution-NonCommercial-ShareAlike 4.0 License, which allows others to remix, tweak, and build upon the work non-commercially, as long as appropriate credit is given and the new creations are licensed under the identical terms.

For reprints contact: reprints@medknow.com

How to cite this article: Singh A, Parkash S, Gupta SK, Soni RK. Severe varicella pneumonia in adults: Seven years' single-center experience from India. Indian J Crit Care Med 2018;22:162-7. 
mortality approaches $50 \%$ in patients requiring mechanical ventilation. ${ }^{[8]}$

Data on severe varicella pneumonia from India are limited to case reports and small case series, so the present study was intended to describe the clinical manifestations, hospital course, treatment, and outcome in adult patients with severe varicella pneumonia.

\section{Subjects and Methods}

This retrospective study was carried out at an 1100-bed tertiary care teaching hospital in Northwest India. The cases of varicella pneumonia were identified by a computerized search of the available medical record database for the past 7 years (January 2010 and December 2016).

During this period, 137 patients with varicella were admitted and 22 had severe varicella pneumonia. Thereafter, the data pertaining to demographic characteristics; risk factor (smoking history, contact with chickenpox patient, varicella vaccine, HIV status, immunosuppressive treatment, and chronic lung disease); clinical manifestations; radiological features; and laboratory investigations were collected on a predesigned structured pro forma.

The diagnosis of varicella was clinical based on fever and characteristic widespread pleomorphic rash. ${ }^{[5]}$ The cases of varicella pneumonia were identified based on the presence of new onset of respiratory symptoms with radiological findings within 10 days following the onset of clinically evident varicella infection. ${ }^{[5]}$

Patients already diagnosed with bronchiectasis, chronic obstructive pulmonary disease, allergic bronchopulmonary aspergillosis, or interstitial lung disease were classified to have chronic lung disease. Patients were defined as immunosuppressed if they met any one of the following criteria: solid organ transplantation, malignancy, and steroid treatment for more than 1 month or were on any other immunosuppressive drugs or HIV seropositive. Hypoxemia severity was assessed using the partial pressure of oxygen $\left(\mathrm{PaO}_{2}\right)$ : fraction of inspired oxygen $\left(\mathrm{FiO}_{2}\right)$ ratio. Acute respiratory distress syndrome (ARDS) was defined in accordance with the Berlin definition. ${ }^{[9]}$ Disease severity was assessed using the quick sequential (sepsis-related) organ failure assessment (qSOFA) score at the time of admission. ${ }^{[10]}$ All the patients were isolated in the closed rooms adjoining the Intensive Care Unit (ICU) as negative airflow rooms were not available, and these patients were looked after by the staff with varicella immunity. Therapeutic regimens (acyclovir, antibiotics, steroids, and varicella-zoster virus immunoglobulins) including the type of respiratory support provided (oxygen supplementation, noninvasive mechanical ventilation [NIV], and invasive mechanical ventilation) were recorded. ICU-acquired infections were recorded. The diagnosis of infection was confirmed if patients met both the microbiological detection of a pathogen and the intention to treat it with the related antibiotics. Length of stay in ICU and hospital and status of patient at ICU and hospital discharge were noted.

The statistical analyses were performed using SPSS software, version 20.0 (SPSS, Inc., Chicago, IL, USA). The percentages of patients in each category were calculated for categorical variables. The mean and standard deviation were computed. The Fisher's Z-test of proportions and analysis of variance were applied to compare the two groups. $P<0.05$ was considered statistically significant.

\section{RESULTS}

During the 7-year study period, 137 patients with varicella were admitted of these $22(16 \%)$ patients who had severe varicella pneumonia.

\section{Demographic and underlying risk factors}

There were 17 (77.3\%) men and 5 (22.7\%) women. Majority of the patients were relatively young (20-43 years), except two patients who were more than 50 years (mean age $33.4 \pm 10.8$ years). History of exposure/contact with a person infected with varicella was evident in all patients [Table 1]. Information regarding immunization with varicella vaccine was not available.

Nearly 45.4\% (10/22) patients were immunosuppressed. Among the immunosuppressed state, corticosteroid use (6/10) was the most common.

\section{Clinical features}

All the patients had an acute presentation with a mean duration of symptom of 4 days (range, 2-7 days) before hospitalization. All the patients had the typical extensive pleomorphic rash and respiratory symptoms. Dyspnea (21/22), fever (18/22), and cough (14/22) were the most common symptoms [Table 2] The comparison between the characteristics of patients requiring invasive mechanical ventilation (ventilated group) during the hospital stay to those who did not require mechanical ventilation (spontaneously breathing group) revealed no difference in the presenting symptoms among the two groups. However, the mean duration from the onset of symptom to hospitalization was significantly $(P=0.001)$ more in the ventilated group $(5.1 \pm 1.5$ days $)$ than the spontaneously breathing group (3.2 \pm 0.6 days).

\section{Laboratory investigations}

Laboratory findings indicated thrombocytopenia in $9(40.9 \%)$, elevated transaminases in $7(31.8 \%)$, and leukopenia in $3(13.6 \%)$ patients. Thrombocytopenia, elevated transaminases, and hypoalbuminemia were significantly more in the mechanically ventilated group as compared to the spontaneously breathing group [Table 3].

All the patients had an abnormal chest radiograph. Nodular (19/22) and interstitial opacities (11/22) were the most common radiographic abnormality. However, airspace disease was significantly $(P=0.001)$ more in the mechanically ventilated 


\begin{tabular}{|c|c|c|c|c|}
\hline Variables & Overall $(n=22)$ & Spontaneous breathing group $(n=12)$ & Intubated group $(n=10)$ & $P$ \\
\hline \multicolumn{5}{|l|}{ Demographics } \\
\hline Age (years), mean $\pm \mathrm{SD}$ & $33.4 \pm 10.8$ & $31.58 \pm 11.4$ & $35.6 \pm 10.2$ & 0.400 \\
\hline Male gender & $17(77.3)$ & $8(66.7)$ & $9(90.0)$ & 0.193 \\
\hline Contact with chickenpox case & $22(100)$ & $12(100)$ & $10(100)$ & 0.000 \\
\hline Underlying immunosuppression & $10(45.4)$ & $3(25.0)$ & $7(70.0)$ & - \\
\hline Steroid treatment & $6(27.2)$ & $1(8.3)$ & $5(50.0)$ & 0.028 \\
\hline Any immunosuppressant & $3(13.6)$ & $1(8.3)$ & $2(20.0)$ & 0.429 \\
\hline Solid organ transplantation & $2(9.1)$ & $1(8.3)$ & $1(10.0)$ & 0.888 \\
\hline Malignancy & $1(4.5)$ & - & $1(10.0)$ & - \\
\hline HIV & $1(4.5)$ & - & $1(10.0)$ & - \\
\hline Tobacco smokers & $4(18.1)$ & $1(8.3)$ & $3(30.0)$ & 0.190 \\
\hline Chronic respiratory disease & $2(9.1)$ & - & $2(20.0)$ & - \\
\hline Pregnancy & $1(4.5)$ & $1(8.3)$ & - & - \\
\hline Comorbidities & $3(13.6)$ & $1(8.3)$ & $2(20.0)$ & 0.429 \\
\hline Diabetes mellitus & $1(4.5)$ & - & $1(10.0)$ & - \\
\hline Hypertension & $1(4.5)$ & $1(8.3)$ & 0 & - \\
\hline Chronic liver disease & $1(4.5)$ & - & $1(10.0)$ & - \\
\hline
\end{tabular}

Figures in parentheses indicate percentages. SD: Standard deviation

\begin{tabular}{|c|c|c|c|c|}
\hline Variables & Overall $(n=22)$ & Spontaneous breathing group $(n=12)$ & Intubated group $(n=10)$ & $P$ \\
\hline Fever & $18(81.1)$ & $10(83.3)$ & $8(80)$ & 0.841 \\
\hline Dyspnea & $21(95.4)$ & $11(91.6)$ & $10(100)$ & 0.352 \\
\hline Cough & $14(68.2)$ & $7(58.3)$ & $7(70)$ & 0.568 \\
\hline Hemoptysis & $3(13.6)$ & - & $3(30)$ & - \\
\hline Chest pain & $3(13.6)$ & $2(16.6)$ & $1(10)$ & 0.652 \\
\hline Mean duration of illness (days)* & $3.8 \pm 1.8$ & $2.9 \pm 1.4$ & $4.9 \pm 1.5$ & 0.020 \\
\hline Temperature $\left({ }^{\circ} \mathrm{C}\right)$, mean $\pm \mathrm{SD}$ & $101.9 \pm 1.4$ & $101.7 \pm 1.4$ & $102.1 \pm 1.5$ & 0.522 \\
\hline BP systolic (mmHg), mean \pm SD & $123.2 \pm 20.5$ & $134.3 \pm 6.9$ & $109.8 \pm 23.6$ & 0.003 \\
\hline $\mathrm{BP}$ diastolic $(\mathrm{mmHg})$, mean $\pm \mathrm{SD}$ & $73.4 \pm 13.5$ & $80.3 \pm 7.7$ & $64.4 \pm 13.8$ & 0.002 \\
\hline $\mathrm{BP}$ mean $(\mathrm{mmHg})$, mean $\pm \mathrm{SD}$ & $89.9 \pm 14.8$ & $98.7 \pm 6.2$ & $79.5 \pm 15.5$ & 0.001 \\
\hline Respiratory rate (bpm), mean $\pm \mathrm{SD}$ & $29.1 \pm 5.5$ & $26.00 \pm 3.0$ & $32.70 \pm 5.5$ & 0.001 \\
\hline Heart rate $(\mathrm{bpm})$, mean $\pm \mathrm{SD}$ & $121.8 \pm 13.1$ & $112.5 \pm 6.8$ & $133.0 \pm 9.5$ & 0.001 \\
\hline Saturation $(\%)$, mean \pm SD & $76.55 \pm 9.9$ & $83.2 \pm 6.5$ & $68.6 \pm 6.9$ & - \\
\hline
\end{tabular}

Figures in parentheses indicate percentages. *Mean duration of illness before hospitalization. BP: Blood pressure; SD: Standard deviation

group $(70 \%)$ compared to the spontaneously breathing group $(16.7 \%)$.

\section{Treatment and outcome}

All the patients received intravenous acyclovir in the dose of $10 \mathrm{mg} / \mathrm{kg} / 8$ hourly for a mean duration of 8 days. None of our patients received treatment with varicella-zoster immune globulin or adjunctive high-dose steroid therapy [Table 4].

At the very outset, 12 patients were managed with supplemental oxygen alone, 7 with NIV and supplemental oxygen, and 3 with invasive mechanical ventilation. NIV failed in 4 and nonrebreather mask in 3 patients who were subsequently intubated and mechanically ventilated. Ten (45.4\%) patients required invasive mechanical ventilation during the hospital stay. Most of the patients were intubated on day 1 after admission. The mean duration from the time of hospitalization to mechanical ventilation was 1.6 days (range; $1-3$ ). All the patients who required mechanical ventilation received empirical antibiotics.

Seven patients had severe ARDS according to the Berlin definition, and all of these patients had underlying immunosuppression. The various factors associated with the need for mechanical ventilation in the present study were $\mathrm{PaO}_{2}: \mathrm{FiO}_{2}$ ratio $<150$ (9/9), chronic lung disease (2/2), qSOFA score $>2(7 / 8)$, early bacterial coinfection (6/7), airspace disease on chest radiograph (7/9), history of smoking (3/4), and immunosuppressed state (7/10) [Table 5]. Vasopressors were required in $7(31.8 \%)$ and renal replacement therapy in $3(13.6 \%)$ patients.

Bacterial coinfection was documented in $10(45.4 \%)$ patients, of these $5(50 \%)$ had early coinfections, within $72 \mathrm{~h}$ after admission. The major sites of coinfections were the lungs $(60 \%)$, bloodstream $(20 \%)$, skin $(10 \%)$, and urinary tract 


\begin{tabular}{|c|c|c|c|c|}
\hline Variables & Overall $(n=22)$ & Spontaneous breathing group $(n=12)$ & Intubated group $(n=10)$ & $P$ \\
\hline Hemoglobin $(\mathrm{g} / \mathrm{dl})$, mean \pm SD & $11.2 \pm 2.5$ & $10.3 \pm 2.5$ & $11.5 \pm 2.1$ & 0.038 \\
\hline $\mathrm{WBCs} / \mu \mathrm{L}, \operatorname{mean} \pm \mathrm{SD}$ & $11.9 \pm 3.9$ & $10.4 \pm 3.8$ & $13.7 \pm 3.6$ & 0.050 \\
\hline Platelet cells $/ \mu \mathrm{L}$, mean $\pm \mathrm{SD}$ & $135.5 \pm 72.3$ & $160.8 \pm 17.1$ & $86.7 \pm 25.5$ & 0.002 \\
\hline Total bilirubin (mg/dl), mean \pm SD & $0.9 \pm 0.4$ & $0.7 \pm 0.3$ & $1.08 \pm 0.5$ & 0.025 \\
\hline $\operatorname{SGOT}(\mathrm{U} / \mathrm{L})$, mean $\pm \mathrm{SD}$ & $113.5 \pm 68.1$ & $75.9 \pm 36.6$ & $158.6 \pm 70.9$ & 0.002 \\
\hline $\mathrm{SGPT}(\mathrm{U} / \mathrm{L})$, mean $\pm \mathrm{SD}$ & $77.9 \pm 52.9$ & $48.4 \pm 21.8$ & $113.4 \pm 58.1$ & 0.002 \\
\hline $\operatorname{ALP}(\mathrm{U} / \mathrm{L}), \operatorname{mean} \pm \mathrm{SD}$ & $112.4 \pm 27.6$ & $108.6 \pm 32.4$ & $122.2 \pm 37.9$ & 0.489 \\
\hline Albumin $(\mathrm{g} / \mathrm{dl})$, mean $\pm \mathrm{SD}$ & $3.3 \pm 0.8$ & $3.6 \pm 0.7$ & $2.9 \pm 0.8$ & 0.049 \\
\hline Urea $(\mathrm{mg} / \mathrm{dl})$, mean $\pm \mathrm{SD}$ & $55.6 \pm 27.4$ & $46.1 \pm 18.4$ & $67.1 \pm 32.7$ & 0.070 \\
\hline Creatinine $(\mathrm{mg} / \mathrm{dl})$, mean $\pm \mathrm{SD}$ & $1.3 \pm 0.5$ & $1.0 \pm 0.3$ & $1.6 \pm 0.6$ & 0.003 \\
\hline Sodium $(\mathrm{mmol} / \mathrm{L}), \operatorname{mean} \pm \mathrm{SD}$ & $131.7 \pm 8.7$ & $133.8 \pm 8.7$ & $129.1 \pm 9.3$ & 0.212 \\
\hline $\mathrm{PaO}_{2}: \mathrm{FiO}_{2}$ ratio $(\mathrm{mmHg})$ & $166.1 \pm 72.3$ & $221.3 \pm 36.5$ & $99.8 \pm 40.3$ & 0.0001 \\
\hline \multicolumn{5}{|l|}{ Chest X-ray at admission } \\
\hline Nodular opacities & $19(86.4)$ & $10(83.3)$ & $9(90.0)$ & 0.652 \\
\hline Interstitial opacities & $11(50)$ & $8(66.7)$ & $3(30.0)$ & 0.087 \\
\hline Airspace disease & $9(40.9)$ & $2(16.7)$ & $7(70.0)$ & 0.001 \\
\hline ARDS & $7(31.8)$ & - & $7(70.0)$ & - \\
\hline
\end{tabular}

Figures in parentheses indicate percentages. SGOT: Serum glutamic-oxaloacetic transaminase; SGPT: Serum glutamic-pyruvic transaminase; ALP: Alkaline phosphatase; ARDS: Acute respiratory distress syndrome; SD: Standard deviation; WBC: White blood cells; $\mathrm{FiO}_{2}$ : Fraction of inspired oxygen

Table 4: Management and outcome of patients with severe varicella pneumonia

\begin{tabular}{|c|c|c|c|c|}
\hline Variables & Overall $(n=22)$ & Spontaneous breathing group $(n=12)$ & Intubated group $(n=10)$ & $P$ \\
\hline qSOFA score & $1.6 \pm 0.9$ & $1.1 \pm 0.3$ & $2.2 \pm 0.9$ & 0.0001 \\
\hline Acyclovir duration & $8.4 \pm 3.6$ & $6.4 \pm 0.7$ & $10.7 \pm 4.2$ & 0.002 \\
\hline Empirical antibiotics at admission & $17(77.2)$ & $7(58.3)$ & $10(100)$ & 0.020 \\
\hline Early bacterial coinfection & $5(22.7)$ & $1(8.3)$ & $4(40)$ & 0.078 \\
\hline Late bacterial coinfection & $5(22.7)$ & - & $5(50)$ & - \\
\hline Vasopressors & $7(31.8)$ & - & $7(70)$ & - \\
\hline Renal replacement therapy & $3(13.6)$ & - & $3(13.6)$ & - \\
\hline \multicolumn{5}{|l|}{ Outcome data } \\
\hline Duration of ICU stay (days) & $5.8 \pm 1.7$ & $4.8 \pm 0.8$ & $8.0 \pm 1.0$ & 0.001 \\
\hline Length of hospital stay (days) & $8.7 \pm 2.9$ & $6.9 \pm 0.7$ & $12.8 \pm 1.3$ & 0.001 \\
\hline Hospital mortality & $5(22.7)$ & - & $5(50)$ & - \\
\hline
\end{tabular}

Figures in parentheses indicate percentages. qSOFA: Quick sequential (sepsis-related) organ failure assessment; ICU: Intensive Care Unit

Table 5: Need for mechanical ventilation in patients with severe varicella pneumonia

\begin{tabular}{lcc}
\hline Risk factor & $\begin{array}{c}\text { Number of } \\
\text { patients }\end{array}$ & $\begin{array}{c}\text { Need for mechanical } \\
\text { ventilation }\end{array}$ \\
\hline $\mathrm{PaO}_{2}: \mathrm{FiO}_{2}$ ratio $<150$ & 9 & $9(100)$ \\
$\mathrm{Chronic}$ lung disease & 2 & $2(100)$ \\
qSOFA score $>2$ & 8 & $7(87.5)$ \\
Early bacterial coinfection & 7 & $6(85.7)$ \\
Airspace disease & 9 & $7(77.8)$ \\
Smoking & 4 & $3(75.0)$ \\
Underlying immunosuppressed state & 10 & $7(70.0)$ \\
Age $>40$ years & 7 & $4(57.1)$ \\
\hline
\end{tabular}

Figures in parentheses indicate percentages. qSOFA: Quick sequential (sepsis-related) organ failure assessment; $\mathrm{FiO}_{2}$ : Fraction of inspired oxygen

infection (10\%). Staphylococcus aureus (30\%), Klebsiella pneumoniae (20\%), and Acinetobacter baumannii (20\%) were the most often recovered pathogen.
The mean ICU and hospital stay of the entire cohort were 7 days (range; 1-16) and 9 days (range; 4-21), respectively. The mortality in the study period was $22.7 \%$. The main causes of death were as follows: septic shock in $3(60 \%)$ and refractory ARDS in $2(40 \%)$ patients. Septic shock in these 3 patients was attributed to superadded ventilator-associated pneumonia. The mortality was higher among patients with qSOFA score $>3(5 / 5)$, mean arterial blood pressure $<60 \mathrm{mmHg}(2 / 2)$, chronic lung disease $(2 / 2)$, early bacterial coinfection (4/5), severe ARDS at presentation (5/7), immunosuppressed state (5/10), and need for mechanical ventilation $(5 / 10)$ [Table 6].

\section{DISCUSSION}

In the present study of 7 years, 22 patients were identified to have severe varicella pneumonia among the 137 admitted patients with varicella. Majority of the patients were young males. There was male preponderance of varicella pneumonia cases in our study which has also been reported in various 


\begin{tabular}{lcc}
\hline $\begin{array}{l}\text { Table 6: Risk factors for mortality in patients with severe } \\
\text { varicella pneumonia }\end{array}$ & Number of patients & Mortality \\
\hline Risk factor & 5 & $5(100)$ \\
\hline qSOFA score $>3$ & 2 & $2(100.0)$ \\
MABP $<60$ mmHg & 2 & $2(100)$ \\
Chronic lung disease & 5 & $4(80.0)$ \\
Early bacterial coinfection & 7 & $5(71.4)$ \\
Severe ARDS at presentation & 7 & $5(71.4)$ \\
Need for vasopressors & 10 & $5(50.0)$ \\
Underlying immunosuppressed state & 10 & $5(50)$ \\
Age $>35$ years & 4 & $2(50)$ \\
Smoking & 10 & $5(50)$ \\
Need for mechanical ventilation & Figures in parentheses indicate percentages. qSOFA: Quick sequential \\
(sepsis-related) organ failure assessment; ARDS: Acute respiratory \\
distress syndrome; MABP: Mean arterial blood pressure
\end{tabular}

other studies. ${ }^{[11,12]}$ The reason for this male predilection is unclear.

A history of exposure to varicella within a month of onset of illness was observed in all the patients, reinforcing the fact that primary varicella is highly contagious disease.

The data on varicella immunization in our cohort was not available, but it is unlikely that our patients had received such vaccination as it is not included in the Indian national immunization schedule. In countries where varicella is included in their vaccination programs, data support its significant role in reducing mortality and preventing complications in all age groups. ${ }^{[13]}$

Underlying immunosuppressed state is a well-known risk factor for varicella pneumonia and was seen in $45.4 \%$ patients. It was mainly related to impaired cellular immune response (immunosuppressive drugs and/or steroid exposure and malignancy). However, we identified 5 (22.7\%) patients with severe varicella pneumonia in apparently young healthy controls, thus reinforcing the fact that varicella pneumonia can occur in an immunocompetent host without any risk factors.

Smoking is a major risk factor for the development of varicella pneumonia in adults; ${ }^{[14]}$ however, only 4 (18.1\%) patients in the present study were smokers. The lower number of smokers in the present study reflects the smoking trends for the state of Punjab. Tobacco prevalence is the lowest for Punjab in India as majority of its population (58\%) practice Sikh religion, which prohibits tobacco consumption..$^{[15]}$

The mean duration of illness prior ICU admission was 4 days (2-7), which is similar to other causes of viral pneumonia. ${ }^{[16,17]}$ The course of illness was quite dramatic in about $45 \%$ of cases characterized by rapid respiratory deterioration, requiring invasive mechanical ventilation, soon after ICU admission. Seventy percent of the patients requiring mechanical ventilation had severe ARDS.

The mean duration from the onset of symptom to hospitalization was significantly $(P=0.001)$ more in the ventilated group ( $5.1 \pm 1.5$ days) than the spontaneously breathing group ( $3.2 \pm 0.6$ days) and may indicate that a delay in seeking medical advice/treatment may increases the risk for respiratory failure and mortality.

All the patients received intravenous acyclovir which is the standard of care for patients with varicella pneumonia. Published data based on 46 retrospective series comprising of 272 patients suggested a 3.6-fold higher mortality in patients who did not receive acyclovir. ${ }^{[2]}$ The use of corticosteroids for severe varicella pneumonia is controversial. None of our patients was treated with systemic steroids. Retrospective series on steroid use in adults with varicella pneumonia have shown a trend toward shorter ICU and hospital stay with no mortality. ${ }^{[18]}$

Bacterial coinfection occurred in 10 (45.3\%), mainly in those who required intubation and invasive mechanical ventilation. A higher number of patients with varicella pneumonia developing bacterial coinfection in the present study may be related to breach in innate immune system due to extensive of skin and mucosal involvement, need for intubation, and presence of coexisting underlying immunosuppressed states which predispose them to a wide range of infections. The reported rate of viral-bacterial coinfection in patients with viral pneumonia varies between $27.6 \%$ and $70.0 \%{ }^{[19,20]}$

The overall mortality in our cohort was $22.7 \%$ and reached $50 \%$ in patients who received invasive mechanical ventilation. Viruses have now been increasingly recognized as pathogens responsible for severe community-acquired pneumonia. In a prospective study in the ICU setting, the mortality rate of patients with viral pneumonia was similar to that of patients with bacterial pneumonia $(25.5 \%$ and $26.5 \% ; P=0.82)$. ${ }^{[21]}$

\section{Limitations of the study}

Ours is a retrospective study over a long period, during which the supportive practices may have changed and influenced the results. We did not have the serological confirmation of varicella. The clinical and laboratory diagnosis of varicella is restricted to unusual cases. Due to the limited number of patients, we could not identify independent predictors of mortality.

\section{Conclusions}

Severe varicella pneumonia in adults is an acute respiratory illness that may require mechanical ventilation in significant number of the cases. Although the underlying medical conditions or immunosuppression is an important risk factor, it can occur in apparently healthy young adults. Delay in seeking medical advice may increase the risk for respiratory failure and mortality. The mortality is high, especially in those requiring invasive mechanical ventilation.

\section{Financial support and sponsorship}

Nil.

\section{Conflicts of interest}

There are no conflicts of interest. 


\section{ReFEREnCES}

1. Kimberlin D, Brady MT, Jackson MA, Long SS. Red Book. $30^{\text {th }}$ ed. USA: American Academy of Pediatrics; 2015. p. 846-60.

2. Nguyen HQ, Jumaan AO, Seward JF. Decline in mortality due to varicella after implementation of varicella vaccination in the United States. N Engl J Med 2005;352:450-8.

3. Mohsen AH, McKendrick M. Varicella pneumonia in adults. Eur Respir J 2003;21:886-91.

4. Gnann JW Jr. Varicella-zoster virus: Atypical presentations and unusual complications. J Infect Dis 2002;186 Suppl 1:S91-8.

5. Mandell GL, Douglas GR, Bennett JE. Principal and Practice of Infectious Diseases. $5^{\text {th }}$ ed. Philadelphia: Churchill Livingston; 2015. p. 1731-7.

6. Nilsson A, Ortqvist A. Severe varicella pneumonia in adults in Stockholm county 1980-1989. Scand J Infect Dis 1996;28:121-3.

7. Centers for Disease Control and Prevention (CDC). Varicella-related deaths among adults - united States, 1997. MMWR Morb Mortal Wkly Rep 1997;46:409-12.

8. Feldman S. Varicella-zoster virus pneumonitis. Chest 1994;106:22S-27S.

9. ARDS Definition Task Force, Ranieri VM, Rubenfeld GD, Thompson BT, Ferguson ND, Caldwell E, et al. Acute respiratory distress syndrome: The berlin definition. JAMA 2012;307:2526-33.

10. Raith EP, Udy AA, Bailey M, McGloughlin S, MacIsaac C, Bellomo R, et al. Prognostic accuracy of the SOFA score, SIRS criteria, and qSOFA score for in-hospital mortality among adults with suspected infection admitted to the Intensive Care Unit. JAMA 2017;317:290-300.

11. Ho BC, Tai DY. Severe adult chickenpox infection requiring intensive care. Ann Acad Med Singapore 2004;33:84-8.

12. Frangides CY, Pneumatikos I. Varicella-zoster virus pneumonia in adults: Report of 14 cases and review of the literature. Eur J Intern Med 2004; 15:364-70.

13. Zhou F, Harpaz R, Jumaan AO, Winston CA, Shefer A. Impact of varicella vaccination on health care utilization. JAMA 2005;294:797-802.

14. Alanezi M. Varicella pneumonia in adults: 13 years' experience with review of literature. Ann Thorac Med 2007;2:163-5.

15. Jindal SK, Aggarwal AN, Chaudhry K, Chhabra SK, D’Souza GA, Gupta D, et al. Tobacco smoking in India: Prevalence, quit-rates and respiratory morbidity. Indian J Chest Dis Allied Sci 2006;48:37-42.

16. Cesario TC. Viruses associated with pneumonia in adults. Clin Infect Dis 2012;55:107-13

17. Domínguez-Cherit G, Lapinsky SE, Macias AE, Pinto R, Espinosa-Perez L, de la Torre A, et al. Critically ill patients with 2009 influenza A(H1N1) in Mexico. JAMA 2009;302:1880-7.

18. Adhami N, Arabi Y, Raees A, Al-Shimemeri A, Ur-Rahman M, Memish ZA, et al. Effect of corticosteroids on adult varicella pneumonia: Cohort study and literature review. Respirology 2006;11:437-41.

19. Jennings LC, Anderson TP, Beynon KA, Chua A, Laing RT, Werno AM, et al. Incidence and characteristics of viral community-acquired pneumonia in adults. Thorax 2008;63:42-8.

20. Johnstone J, Majumdar SR, Fox JD, Marrie TJ. Viral infection in adults hospitalized with community-acquired pneumonia: Prevalence, pathogens, and presentation. Chest 2008;134:1141-8.

21. Choi SH, Hong SB, Ko GB, Lee Y, Park HJ, Park SY, et al. Viral infection in patients with severe pneumonia requiring Intensive Care Unit admission. Am J Respir Crit Care Med 2012;186:325-32. 